\title{
Effect of an educational intervention on the breastfeeding technique on the prevalence of exclusive breastfeeding
}

\author{
Tâmara Oliveira de Souza 1 \\ iD https://orcid.org/0000-0001-9150-4877 \\ Thaize Estrela do Vale Morais 2 \\ https://orcid.org/0000-0002-2543-5153 \\ Camilla da Cruz Martins 3 \\ https://orcid.org/0000-0002-6946-4618 \\ José de Bessa Júnior 4 \\ https://orcid.org/0000-0003-4833-4889 \\ Graciete Oliveira Vieira 5 \\ (iD) https://orcid.org/0000-0001-5354-718X
}

1-5 Universidade Estadual de Feira de Santana. Av. Transnordestina. s.n. BR 116. Feira de Santana, BA, Brasil. CEP: 44.036-900. E-mail: tamara@uefs.br

\begin{abstract}
Objectives: to evaluate the effect of an intervention directed to the breastfeeding technique in the prevalence of exclusive breastfeeding in the first month of life.

Methods: this is a quasi-randomized intervention study conducted in a public maternity ward accredited in the Baby-Friendly Hospital Initiative. The intervention consisted of individual orientations on the breastfeeding technique in the first 48 hours after delivery, with the help of a breast model, doll, and movie. The control group was oriented by researchers about the importance of breastfeeding, and received hospital orientations. Data were collected in the maternity ward, and at the end of the first month in the hospital's outpatient service by implementing a questionnaire, observing the baby's breastfeeding technique and examining breasts.

Results: the prevalence of exclusive breastfeeding in the first month of life of the infant was $76.6 \%$ in the experimental group, and $52.2 \%$ in the control group. $R R=1.46$ $(C 195 \%=1.16-1.84) ; N N T=4.09 ; p=0.001$. The trained women presented a correct breastfeeding technique in $64.04 \%$, much higher when compared to those who did not receive training $(15.11 \% ; R R=4.87[C I 95 \%=2.93-8.34] ; N N T=1.96 ; p<0.001)$.

Conclusions: the use of audiovisual resources, use of instruments (model breast and doll), and type of individualized approach contributed to an increased prevalence of exclusive breastfeeding up to 30 days after delivery.
\end{abstract}

Palavras-chave Breastfeeding, Intervention, Prevalence

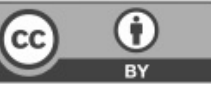




\section{Introduction}

The practice of breastfeeding is fundamental to children's health. Exclusive breastfeeding has several benefits, such as protection against gastrointestinal and respiratory diseases, with an impact on reducing child mortality, ${ }^{1}$ as well as against chronic diseases such as type II diabetes and obesity, ${ }^{2}$ and helps in cognitive development, 3 among other benefits.

The recommendation of exclusive breastfeeding in the first six months of the child's life and its maintenance for two years or more is consensual. 4 Despite the significant improvement in Brazilian breastfeeding indicators, in the last decades, the early interruption of exclusive breastfeeding remains a public health problem. 5,6

Some difficulties in the breastfeeding process that evolve to early weaning are related to maternal characteristics, for example, being a young mother, 5 having low household income, 7 maternal work outside the home, 7,8 low schooling, being a single mother, absence of previous experience with breastfeeding, 7,9 being unaware of the breastfeeding's benefits, lack of guidance on breastfeeding in the maternity ward, 10 and nipple fissure as a consequence of the inadequate breastfeeding technique.11

The incorrect breastfeeding technique is a difficulty faced by the nursing mother, which can be identified before hospital discharge. When not corrected, it can lead to nipple trauma, 11 breast engorgement, low milk production, the unnecessary introduction of complementary foods, and early weaning.4,12,13 It is a determinant of the interruption of exclusive breastfeeding, which can be modified through intervention strategies. Given this situation, this paper brings to the fore a guiding question: if the woman is appropriately guided on the correct breastfeeding technique, will she be able to breastfeed her baby in the first month of life exclusively?

The topic at hand is relevant, as educational actions improve the rates of initiation, duration of breastfeeding and exclusive breastfeeding.13-15 Strategies must be conducted to solve the difficulties that arise in the first and second postpartum weeks, a period of increased risk of early weaning. 16

This study aimed to evaluate the effect of an educational intervention directed to the breastfeeding technique on the prevalence of exclusive breastfeeding in the first month of life.

\section{Methods}

This is a quasi-randomized intervention study with the breastfeeding technique as an independent vari- able and the prevalence of exclusive breastfeeding in the first month after delivery as the outcome. The intervention consisted of teaching and demonstrating systematically to the experimental group the correct breastfeeding technique in the first 48 hours after delivery. In the control group, puerperae were instructed on the importance of breastfeeding, and both groups received standardized hospital guidelines without distinction.

The current study was approved by the Research Ethics Committee of the State University of Feira de Santana under opinion CAAE $\mathrm{n}^{\circ}$ 39286514.0.0000.0053, complying with the rules of the National Health Council and the Research Ethics Committee (CONEP), Resolution 466/12. Data were collected after signing the informed consent form.

The surveyed participants were the puerperaenewborns pairs living in Feira de Santana, State of Bahia, Brazil, whose deliveries took place in a hospital with the Baby-Friendly Hospital Initiative, located in this city, where 4,504 deliveries occurred in 2013.

When calculating the sample, assuming an alpha error of $5 \%$ with a beta error (power) of $80 \%$, a $59.3 \%$ prevalence of exclusive breastfeeding was assumed, as demonstrated in a previous study. 9 Moreover, a minimum difference of $20 \%$ was calculated so that the result of the intervention would be considered significant. It required 180 pairs, 90 allocated to the control group, and 90 to the experimental group. A $20 \%$ increase was applied to cater for possible losses, arriving at a total of 216 pairs.

The exclusion criteria for the sample were twin babies, those admitted to the neonatal unit, or women with any breastfeeding contraindications. A pilot study was carried out with nine mothers, corresponding to $5 \%$ of the sample, and the study logistics and data collection instruments were tested, with subsequent review of the forms and necessary adjustments.

In the maternity ward, maternal identification information, sociodemographic characteristics, variables related to pregnancy, and data on the knowledge and experience of the puerperae were collected. Regarding the infant, data were collected regarding birth and feeding. Exclusive breastfeeding was defined as infants who received only breast milk, directly from the breast or expressed human milk and no other liquid or solid food, except for drops or syrups of vitamins, minerals or medicines. 4 The breastfeeding technique was assessed using the instrument recommended by the World Health Organization, ${ }^{4}$ which includes criteria for body posture (positioning) of the pair, reflexes and 
responses of the baby during breastfeeding, signs of bonding, anatomy of the breast and signs of suction during grip. The breastfeeding technique was considered to be incorrect when at least one criterion was inadequate.

A simple draw was carried out in the first week, beginning data collection by the experimental group. The pairs of puerperae/newborns were selected daily among the pregnant women who gave birth in the 48 hours before data collection until the minimum number of participants calculated for the research was reached.

The subjects were allocated in bloc, as the data collection of the puerperae who were part of the experimental and control groups occurred in alternate weeks, so that the mothers of the respective groups stayed in different wards, thus preventing the women in the control group from feeling discredited due to differences in attention and approaches provided to the experimental group, as well as avoiding the cross-referencing of information that could interfere with the results. As new losses occurred, pairs were selected until the minimum number of participants was reached.

Of the 216 pairs selected for the study, 36 (16.6\%) were lost during the follow-up, which resulted in 180 pairs, distributed as follows: 90 in the control group and 90 in the intervention group (Figure 1).

Data were collected on two occasions: at the maternity ward and 30 days after delivery, at the pediatric outpatient service of the hospital itself. When the mother did not attend the visit with the pediatrician, a home visit was made with a prior appointment by telephone. Data were collected by two nurses and a nutritionist, responsible for selecting the sample, interviewing the mothers, observing the breasts, and assessing feeding. All were trained in the collection procedures.

Concerning the object of the current study, breastfeeding was observed in the experimental group during the hospital approach. Then the intervention was carried out in three stages: first stage showing the 22-minute video "Breastfeeding is much more than feeding the child" (free translation from Portuguese) produced by the Ministry of Health, in which it addresses the correct breastfeeding technique and the benefits of breastfeeding. This exhibition was held individually or in groups of a maximum of three women, with the presence of one of the researchers. Moreover, a specific selection of the video about breastfeeding technique was demonstrated with the help of a computer; second stage - verbal guidance on the benefits of breast milk, appropriate clothing that facilitates the exposure of the breast, position of the mother and child, with the head and body aligned and facing the mother's body (belly to belly), chin touching the breast, facing the nipple, grip the mother's breast with a wide-open mouth, grabbing the whole nipple and most of the areola; and the third stage - individualized demonstration of the breastfeeding technique using the model breast and doll. The mother repeated the procedures taught with her child and appropriate guidance was provided if an unfavorable parameter of the breastfeeding technique was identified. Any concern was clarified at the end of the intervention.

The guidelines provided during the intervention differed from those that already occurred routinely in the hospital, concerning the use of different resources in the same approach (breast model, doll, and video), to the type of individual approach (specific video about technique, demonstration of breastfeeding technique and breastfeeding observation) or in groups of a maximum of three women, and was applied only to the Ministry of Health video.

In the hospital approach, the procedures performed by the researchers for the control group were the application of the same questionnaire as the experimental group and the provision of guidelines on the benefits of breastfeeding. Furthermore, they followed the hospital's routines, which consisted of guidance and distribution of explanatory leaflets on breastfeeding management.

Thirty days after birth, the mothers and their respective infants from both the control and experimental groups returned to the same hospital for the childcare visit with the institution's pediatrician. In this approach, the procedures were the same for the experimental and control group. During the waiting period for a medical visit, the follow-up form was applied as an interview, which sought information on the infant's dietary pattern. A specific questionnaire on nipple trauma was also applied, which was the object of another study. Finally, the observation of breastfeeding was performed by completing the form recommended by the World Health Organization, ${ }^{4}$ and the examination of the breasts was carried out to investigate nipple trauma.

Statistical Analyses - The Statistic Package for Social Sciences (SPSS), version 10.0, was used for the preparation of the database and statistical analysis. The absolute and relative frequencies of all the variables collected were computed, with the characterization of the control group and the experimental group. The frequencies of the parameters 
Flow diagram of the progress through the phases of an intervention study.

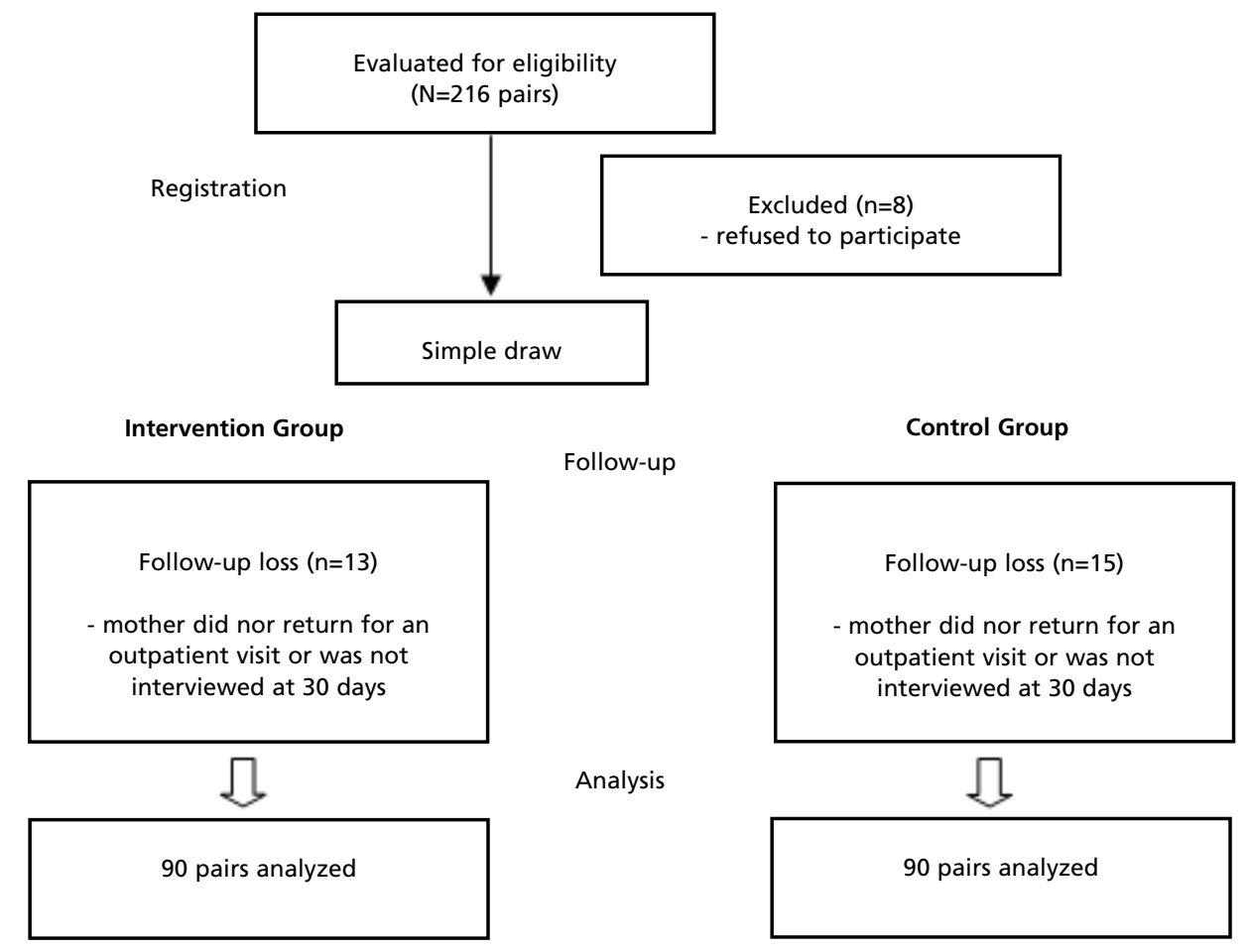

observed during breastfeeding were compared between the pairs. Pearson's chi-square test and Fisher's test were used. The level of significance was set at $p \leq 0.05$, with a $95 \%$ confidence interval Relative Risk and the Number Needed to Treat (NNT), which represents the estimated number of individuals who must receive an intervention to produce a positive outcome, were also calculated. NNT is equivalent to the reciprocal of absolute risk reduction or risk difference. 17

\section{Results}

A total of 180 pairs (mothers and newborns) were evaluated. The experimental and control groups were quite similar, both in the characteristics of mothers and newborns. The mean age of the control group was $25.92 \pm 6.95$, and the experimental group $24.96 \pm 6.67$, with $p=0.821$. The other characteristics are described in Table 1.

In the group that received the intervention, a higher prevalence of exclusive breastfeeding was observed in the first month of life when compared to the controls: $76.6 \%(69 / 90)$ and $52.2 \%(47 / 90)$, respectively. $\quad \mathrm{RR}=1.46 \quad[\mathrm{CI} 95 \%=1.16-1.84]$; $\mathrm{NNT}=4.09[\mathrm{CI} 95 \%=2.64-10.31] ; p=0.001$.
Likewise, women in the experimental group had the correct breastfeeding technique at 30 days in a significantly higher proportion than those in the control group: $64 \%(57 / 89)$ versus $15 \%(13 / 86)$. $\mathrm{RR}=4.87 \quad[\mathrm{CI} 95 \%=2.93-8.34] ; \quad \mathrm{NNT}=1.96$ [CI95\% $=1.61-2.72] ; p<0.001$.

The unfavorable parameters of the breastfeeding technique were significantly lower among the pairs in the experimental group at 30 days of age, for baby positioning (baby away from the mother, chin not touching the breast and baby not supported), baby's response (baby does not maintain the areola grip), emotional bonding (mother and baby hardly touch), grip (mouth slightly open, non-asymmetrical grip and lower lip turned inwards) and suction (just quick sucking with clicking sounds) (Table 2).

\section{Discussion}

The prevalence of exclusive breastfeeding in the current study was $76.6 \%$ in the experimental group and $52.2 \%$ in the control group, 1.46 times more likely for women to practice exclusive breastfeeding in the infant's first month of life. It was also demonstrated that the intervention performed had a positive effect on the breastfeeding technique in the experi- 


\begin{tabular}{|c|c|c|c|c|c|}
\hline \multirow[t]{2}{*}{ Covariates } & \multicolumn{2}{|c|}{$\begin{array}{l}\text { Experimental } \\
\text { Group }\end{array}$} & \multicolumn{2}{|c|}{$\begin{array}{l}\text { Control } \\
\text { Group }\end{array}$} & \multirow[t]{2}{*}{$p^{*}$} \\
\hline & $\mathrm{n}$ & $\%$ & $\mathrm{n}$ & $\%$ & \\
\hline \multicolumn{6}{|l|}{ Characteristics of puerperae } \\
\hline Overweight or obesity** & 46 & 68.7 & 38 & 52.0 & 0.20 \\
\hline Mother with more than 9 years schooling & 50 & 55.6 & 49 & 54.4 & 0.88 \\
\hline Couple living together & 79 & 87.8 & 74 & 82.2 & 0.29 \\
\hline Household income $>1$ minimum wage & 31 & 41.9 & 39 & 48.8 & 0.39 \\
\hline Tobacco use & 3 & 3.3 & 2 & 2.2 & 0.65 \\
\hline Vaginal delivery & 60 & 66.7 & 50 & 55.6 & 0.12 \\
\hline Primiparity & 43 & 47.8 & 38 & 42.2 & 0.45 \\
\hline Pre-natal carewith $\geq 6$ visits & 59 & 67.0 & 52 & 57.8 & 0.23 \\
\hline Guidance on breastfeeding technique in prenatal care & 28 & 31.8 & 39 & 43.3 & 0.12 \\
\hline Guidance on the importance of breastfeeding in prenatal care & 41 & 47.8 & 50 & 56.2 & 0.11 \\
\hline Participation in breastfeeding course in prenatal care & 5 & 5.7 & 12 & 13.3 & 0.12 \\
\hline Has previous breastfeeding experience & 44) & 48.8 & 51 & 56.6 & 0.37 \\
\hline Mean breastfeeding time with previous children $\geq 6$ months*** & 38 & 84.4 & 42 & 80.8 & 0.63 \\
\hline Breast engorgement in the maternity ward & 3 & 3.3 & 2 & 2.2 & 0.66 \\
\hline \multicolumn{6}{|l|}{ Characteristics of the newborn } \\
\hline Female & 49 & 54.4 & 50 & 55.6 & 0.88 \\
\hline Birth weight $<2500$ grams & 3 & 3.3 & 8 & 8.9 & 0.11 \\
\hline Use of pacifier in the maternity ward & 4 & 4.4 & 5 & 5.6 & 0.73 \\
\hline Received supplementation in the maternity ward & 3 & 3.4 & 2 & 2.2 & 0.64 \\
\hline Breastfed in the first hour after delivery & 30 & 33.3 & 21 & 23.3 & 0.14 \\
\hline
\end{tabular}

* Pearson's chi-square test and Fisher's test; * Considering mothers who reported weight and height: $67 \mathrm{from}$ the experimental group and 73 from the control group; $* \star *$ Considering mothers whose first child was one year of age or older: 45 from the experimental group and 52 from the control group.

mental group, which was 4.87 more likely to present the correct technique. In summary, breastfeeding at 30 days was $50 \%$ greater and adequate technique was $500 \%$ more frequent.

Other studies have also found similar results regarding the prevalence of exclusive breastfeeding. The intervention of an interactive section with the mother on breastfeeding technique in the maternity ward showed a positive effect on exclusive breastfeeding rates, ${ }^{18}$ through an intervention that consisted of observing and correcting the grip at the first feeding. 19

International studies have also recorded an increase in breastfeeding rates after the application of the intervention. Guidance on the breastfeeding technique right after delivery and on several occasions during the mother's hospitalization in the maternity ward, 20 as well as group guidance on the breastfeeding technique for pregnant women with more than 36 weeks of gestation, was very successful.21
On the other hand, other studies that carried out only a single intervention on the breastfeeding technique in the maternity ward did not notice an improvement in the quality of the breastfeeding technique and impact on exclusive breastfeeding rates, 12,22,23 even when using images (photos), doll and model breast. ${ }^{23}$ We believe that further use of audiovisual resources (film) by the researchers in a single session may have contributed to the best results found in this intervention.

The intervention was carried out in a maternity ward with the Baby-Friendly Hospital Initiative, which routinely provides guidance on breastfeeding and has a Human Milk Bank. Our findings show the importance of group and individual supplementary educational actions, as well as the simultaneous use of audiovisual resources in association with the use of instruments such as the model breast to demonstrate the breastfeeding technique. Face-to-face guidance is usually more effective, 24 when compared to counseling, being it carried out individually or only 
Frequencies of unfavorable parameters noted in the observation of the breastfeeding technique in mothers and newborns at 30 days after delivery.

\begin{tabular}{|c|c|c|c|c|c|}
\hline \multirow[t]{2}{*}{ Covariates } & \multicolumn{2}{|c|}{$\begin{array}{l}\text { Experimental } \\
\text { Group }\end{array}$} & \multicolumn{2}{|c|}{$\begin{array}{l}\text { Control } \\
\text { Group }\end{array}$} & \multirow[t]{2}{*}{$p^{*}$} \\
\hline & $\mathrm{n}$ & $\%$ & $\mathrm{n}$ & $\%$ & \\
\hline \multicolumn{6}{|l|}{ Mother-baby position } \\
\hline Mother with tense shoulders & 4 & 4.5 & 10 & 11.4 & 0.090 \\
\hline Baby far from mother & 7 & 7.9 & 27 & 30.7 & $<0.001$ \\
\hline Unaligned baby (baby's neck twisted) & 6 & 6.7 & 13 & 14.9 & 0.080 \\
\hline Chin does not touch the breast & 3 & 3.4 & 28 & 31.8 & $<0.001$ \\
\hline Baby not supported (only shoulder or head supported) & 2 & 2.2 & 21 & 23.9 & $<0.001$ \\
\hline \multicolumn{6}{|l|}{ Baby responses } \\
\hline No response to the breast & 1 & 1.1 & 3 & 3.4 & 0.306 \\
\hline No search for breast & 1 & 1.1 & 2 & 2.3 & 0.547 \\
\hline Baby is not interested in the breast & 2 & 2. & 2 & 2.3 & 0.982 \\
\hline Baby restless or crying & 1 & 1.1 & 4 & 4.6 & 0.165 \\
\hline Baby does not keep a grip on the areola & 2 & 2.2 & 24 & 27.6 & $<0.001$ \\
\hline No sign of milk ejection & 4 & 4.5 & 6 & 7.0 & 0.479 \\
\hline \multicolumn{6}{|l|}{ Emotional attachment } \\
\hline Nervous mother or holds the baby wobbly & 0 & - & 2 & 2.3 & 0.153 \\
\hline No mother-baby eye contact & 0 & - & 2 & 2.3 & 0.153 \\
\hline Mother and baby barely touch & 9 & 10.1 & 22 & 25.0 & 0.009 \\
\hline \multicolumn{6}{|l|}{ Anatomy } \\
\hline Engorged breasts & 0 & - & 3 & 3.4 & 0.079 \\
\hline Flat or inverted nipples & 12 & 13.5 & 5 & 5.9 & 0.091 \\
\hline Breast tissue with cracks/redness & 1 & 1.1 & 1 & 1.2 & 0.981 \\
\hline Breasts look stretched or drooping & 1 & 1.1 & 2 & 2.3 & 0.554 \\
\hline \multicolumn{6}{|l|}{ Baby's grip } \\
\hline Mouth slightly open & 7 & 7.9 & 20 & 22.7 & 0.006 \\
\hline Non-asymmetric grip (more areola below baby's mouth) & 13 & 14.6 & 43 & 49.4 & $<0.001$ \\
\hline Lower lip turned inward & 13 & 14.6 & 37 & 42.0 & $<0.001$ \\
\hline \multicolumn{6}{|l|}{ Suction } \\
\hline Just quick suctions with smacks & 0 & - & 9 & 10.3 & 0.002 \\
\hline Loud noises are heard, but not swallowing & 2 & 2.2 & 7 & 8.0 & 0.081 \\
\hline \multicolumn{6}{|l|}{ Suction time } \\
\hline$>15$ minutes & 34 & 38.2 & 29 & 33.7 & 0.537 \\
\hline
\end{tabular}

* Pearson's chi-square test and Fisher's test.

in groups. 25

The calculation of the NNT estimated that one in every two mothers who were instructed on the breastfeeding technique performed it correctly. Likewise, one in every four women who were instructed on the breastfeeding technique, only one practiced exclusive breastfeeding at 30 days. The lower the value of the NNT, the higher the benefit of the intervention. The magnitude of the effect of the intervention reinforces the importance of maternal guidance and can positively influence health professionals in the process of valorization of efforts in guiding the quality of the breastfeeding technique and its impact on breastfeeding indicators. 
The unfavorable parameters of the breastfeeding technique were significantly lower among the pairs in the experimental group at 30 days of life when compared to the control group. These findings are described in other studies as predictors of early weaning. ${ }^{12,19}$ A more specific approach to these parameters may make breastfeeding more adequate and contribute to greater adherence in the future.

The possible limitations from the allocation in blocs and losses between the training and the evaluation of 30 days, despite being not ideal, in our understanding, had little impact on the conclusions since the compared groups showed very similar characteristics, and the sample size was evaluated as sufficient to reject the null hypothesis with an absolute risk reduction of $20 \%$.

We can demonstrate that the intervention on the breastfeeding technique conducted in the maternity ward, in groups and face-to-face, with the help of the model breast, doll, and audiovisual resources had a positive effect on the quality of the technique and the prevalence of exclusive breastfeeding at the end of the first month after delivery.

\section{Authors' contribution}

Souza TO participated in the design, data collection, data analysis, and drafting of the paper. Morais TEV participated in planning, data collection, and analysis. Martins CC and Bessa Júnior J contributed to data analysis, interpretation of results, and revision of the manuscript. Vieira GO participated in the planning, interpretation of results, and writing of the manuscript. All authors approved the final version of the article.

\section{References}

1. Sankar MJ, Sinha B, Chowdhury R, Bhandari N, Taneja S, Martines J, Bahl R. Optimal breastfeeding practices and infant child mortality: a systematic review and metaanalysis. Acta Paediatr. 2015; 104 (Supl. 467): 3-13.

2. Horta BL, Mola CL, Victoria CG. Long-term consequences of breastfeeding on cholesterol, obesity, systolic blood pressure and type 2 diabetes: a systematic review and metaanalysis. Acta Paediatr. 2015; 104 (Supl. 467): 30-7.

3. Horta BL, Mola CL, Victoria CG. Breastfeeding and intelligence: a systematic review and meta-analysis. Acta Paediatr. 2015; 104 (Supl. 467): 14-19.

4. WHO (World Health Organization). Infant and young child feeding: model chapter for textbooks for medical students and allied health professionals. Geneva; 2009.

5. Bezerra VLVA, Nisiyama AL, Jorge AL, Cardoso RM, Silva EF, Tristão RM. Aleitamento Materno exclusivo e fatores associados a sua interrupção: estudo comparativo entre 1999 e 2008. Rev Paul Pediatr. 2012; 30 (2): 173-9.

6. Boccolini CS, Boccolini PMM, Monteiro FR, Venâncio SY, Giugliani ERJ. Tendência de indicadores do aleitamento materno no Brasil em três décadas. Rev SaúdePública. 2017; 51: 108 .

7. Boccolini CS, Carvalho ML, Oliveira MI. Factors associated with exclusive breastfeeding in the first six months of life in Brazil: a systematic review. Rev Saúde Pública. 2015; 49: 91. Disponível em: www.ncbi.nlm.nih.gov/ pubmed/26759970.

8. Vieira TO, Vieira GO, Oliveira NF, Mendes CMC, Giugliani ERJ, Silva LR. Durationof exclusive breastfeeding in a Brazilianpopulation: new determinants in cohortstudy. BMC Pregnancy and Childbirth. 2014; 14: 175. Disponívelem: <http://www.biomedcentral.com/14712393/14/175>

9. Vieira GO, Martins CC, Vieira TO, Oliveira NF, Silva LR. Fatores preditivos da interrupção do aleitamento materno

exclusivo no primeiro mês de lactação.J Pediatr. 2010;86 (5): 441-4.

10. Rocci E, Fernandes RAQ. Dificuldades no aleitamento materno e influência no desmame precoce. RevBrasEnferm. 2014; 67 (1): 22-7.

11. Santos KJS, Santana GS, Vieira TO, Santos CAST, Giugliani ERJ, Vieira GO. Prevalence and factors associated with cracked nipples in the first month postpartum. BMC Pregnancy Childbirth. 2016; 16: 209-16.

12. Weigert EMI, Giugliane ERJ, França MCT, Oliveira LD Bonilha A, Espírito Santo LC, Kõhler CVF. Influência da técnica de amamentação nas frequências de aleitamento materno exclusivo e lesões mamilares no primeiro mês de lactação. J Pediatr. 2005; 81 (4): 310-6.

13. WHO/Unicef (World Health Organizathion/United Nations Children's Fund). Implementation guidance: protecting, promoting, and supporting breastfeeding in facilities providing maternity and newborn services. Geneva; 2018.

14. Patel S, Patel S. The Effectiveness of Lactation Consultants and Lactation Counselors on Breastfeeding Outcomes. J Hum Lactation. 2016; 32 (3): 530-41.

15. Balogun OO, O'Sullivan EJ, McFadden A, Ota E, Gavine A, Garner CD, Renfrew MJ, MacGillivray S. Interventions for promoting the initiation of breastfeeding. Cochrane Database Syst Rev. 2016; 9 (11): CD001688.

16. Wagner EA, Chantry CJ, Dewey KG, Nommsen-Rivers LA Breastfeeding concerns at 3 and 7 days postpartum and feedingstatus at 2 months. Pediatrics. 2013; 132 (4): e86575

17. Oliveira Filho PF. Epidemiologia e bioestatística: fundamentos para a leitura crítica. 1 ed. Rio de Janeiro: Rubio; 2015 .

18. Rodrigues DP, Matte BC, Pedron CD, Kohler CVF, Pinto DGC, Weight E, Espírito Santo LC, Oliveira LD, Bohn M, 
França M, Oliveira PB. Impacto da intervenção na técnica de amamentação e no padrão de aleitamento materno no primeiro mês de vida. Salão de Iniciação Científica, 15; 24 28 nov 2003; [Trabalhos científicos]. Porto Alegre, RS Departamento de Pediatria e Puericultura, Faculdade de Medicina, UFRGS, Sessão 26, n 219 , p. 624, 2003. [acesso em 20 mar 2018]. Disponível em: https://www.lume.ufrgs. $\mathrm{br} /$ handle/10183/48900

19. Pereira MA, Levy L, Matos MA, Calheiros JM. Influência da correção da pega no sucesso do Aleitamento Materno: resultados de um estudo experimental. Rev Referência. 2008; 2(6): 27-38.

20. Ingran J, Johnson D, Greenwood R. Breastfeeding in Bristol: teaching good positioning, and support fathers and families. Midwifery.2002; 18(2): 87-101.

21. Duffy EP, Percival P, Kershaw E. Positive effects of an antenatal group teaching session on postnatal nipple pain nipple trauma and breastfeeding rates. Midwifery. 1997; 13(4): 189-96

22. Henderson A, Stamp G, Pincombe J. Postpartum positioning and attachment education for increasing breastfeeding: a randomized trial. Birth.2001; 28(4): 236-42.

Received on March 8, 2019

Final version presented on November 6, 2019

Approved on December 18, 2019
23. Oliveira LD. Efeito de intervenção para melhorar a técnica de amamentação nas frequências de aleitamento materno exclusive e problemas decorrentes da lactação [dissertação] Porto Alegre: Faculdade de Medicina da Universidade Federal do Rio Grande do Sul; 2004.

24. McFadden A, Gavine A, Renfrew MJ, Wade A, Buchanan P, Taylor JL, Veitch E, Rennie AM, Crowther SA, Neiman S, MacGillivray S. Support for healthy breastfeeding mothers with healthy term babies. Cochrane Database Syst Rev. 2017; 28(2): CD001141.

25. Harron S, Das JK, Salam RA, Imdad, A, Bhutta ZA. Breastfeeding promotion interventions and breastfeeding practices: a systematic review.BMC Public Health. 2013; 13 (Supl. 3): S20 